\title{
Research on properties of solidified loess with calcined ginger nuts in rammed earth for sapping area of earthen sites
}

\author{
Qifeng $\mathrm{Li}^{1}$, Bing Dang ${ }^{1}$, Chuipeng Kong ${ }^{1}$, Erxing Peng ${ }^{2,}$, Wei $\mathrm{Cao}^{2}$, Xiaoying $\mathrm{Hu}^{3}$, and Dandan $\mathrm{Li}^{3}$ \\ ${ }^{1}$ The Third Institute of Geology and Minerals Exploration, Gansu Provincial Bureau of Geology and Minerals Exploration and \\ Development, Lanzhou, China \\ ${ }^{2}$ State Key Laboratory of Frozen Soil Engineering, Northwest Institute of Eco-Environment and Resources, Chinese Academy of \\ Sciences, Lanzhou, China \\ ${ }^{3}$ School of Civil Engineering, Lanzhou University of Technology, Lanzhou, China
}

\begin{abstract}
As a non-toxic and pollution-free curing agent, calcined ginger nuts is introduced to protect rock soil cultural relics recently. In order to study the weatherability, chroma and mechanical properties of solidified loess with calcined ginger nuts, based on the reinforcement project of sapping area of Niutoucheng site in Lintan County of China, a series of tests were conducted at different ages. The results show that the properties of solidified loess are related to the dosage and curing ages. With the increase of dosage and ages, the anti disintegration and anti shrinkage properties are improved, and the mechanical properties are also improved. This study validates that as a new material, calcined ginger nuts is an effective curing agent for rammed earth to reinforce earthen sites. Moreover, the study provides support for its application in earthen sites and reveals its potential engineering practical value.
\end{abstract}

\section{Introduction}

Earth sites are relics left over from various activities such as production and living in human history, and they are an important cultural relic resource [1-4]. China has a long history and extremely rich earth sites resources which has outstanding historical, artistic and cultural value [5]. However, these archaic earth sites face serious diseases, such as sapping, collapse, crevices, flaky denudation and gullies, and current state is not good [6-9]. The damage mainly comes from the natural and man-made threat factors [10]. In addition, the natural destruction process is long and its speed is slow, the harm result of man-made threat is obvious but its duration is short. Both natural and human factors work together to cause serious damage to the earthen sites. Among the above diseases, the sapping problem is the most prominent.

For reinforcing sapping area, mainly technology including rammed earth and adobe masonry [11-12], which has also been applied to the protection of the site body in the large area wall foundation cut and collapse areas [13]. Comparing adobe masonry, ram not only keep better compatibility with earthen sites, but also rammed soil has strong stability and strong ability to resist wind erosion, rain erosion [14]. However, there are some shortcomings, for example, vibrations induced by rammed earth will impact the site ontology [15-19].

Recently, as curing agent, calcined ginger nuts was gradually introduced in rammed earth reinforcing earth sites. Its main mineral composition is $70 \% \sim 80 \%$ calcium carbonate and $20 \% \sim 30 \%$ clay [20]. Li et al. [21] studied the curing mechanism of calcined ginger nuts and found that it mainly included hydration reaction and carbonation reaction. Li et al. [22, 23] compared chemical composition and physical property of two kind of traditional silicate materials, ginger nuts material and age, used in reinforcing ancient architecture. The study found that the modified ginger nuts could be used for repairing and reinforcing the stone, earthen, brick and ceramic relics. Zhang et al. [24] took mixture calcined ginger nuts and clay as grouting material to repair crack in earth sites, and conducted laboratory tests to reveal its physical and hydrological properties. Zhao et al. [25] studied the effect of calcination temperature of $700-1400^{\circ} \mathrm{C}$ on modified ginger nuts material. The research suggests that ginger nuts have a combining characteristic of hydraulicity and nonhydraulicity.

For introducing calcined ginger nuts in earth sites field, the previous studies mainly focused on its composition, curing mechanism and application as grouting material. However, as a kind of non-toxic, pollution-free material, it can also be used in sapping area reinforcement in earth sites. Therefore, as curing agent of rammed soil, its mechanical properties and weatherability were studied in this paper to provide theoretical basis for its application in reinforcement soil site.

\section{Materials}

\footnotetext{
${ }^{*}$ Corresponding author: erxingpeng@1zb.ac.cn
} 
The loess near Niutoucheng site in Lintan County in China was used as rammed soil and calcined ginger nuts as curing agent. Loess and calcined ginger nuts are shown in Figure 1. The basic physical properties and parameters of the loess were tested according to the Standard of Geotechnical Test Methods (GB/T501232019) [26]. Figure 2 shows the particle size distribution curve of loess, and Table 1 shows its basic physical properties.

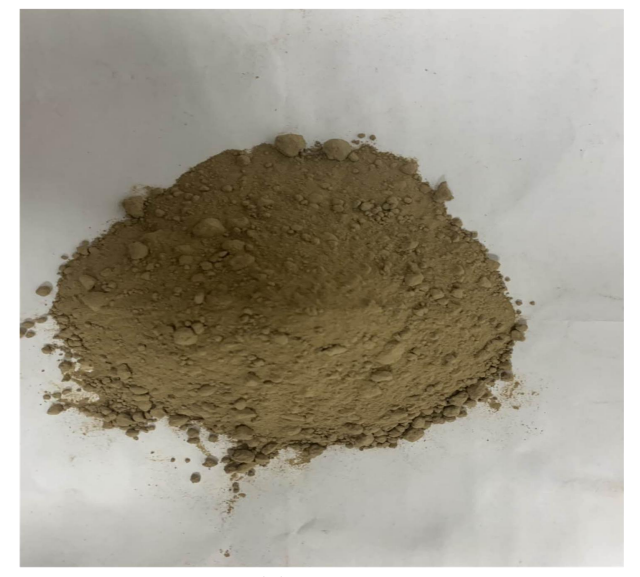

(a) Loess

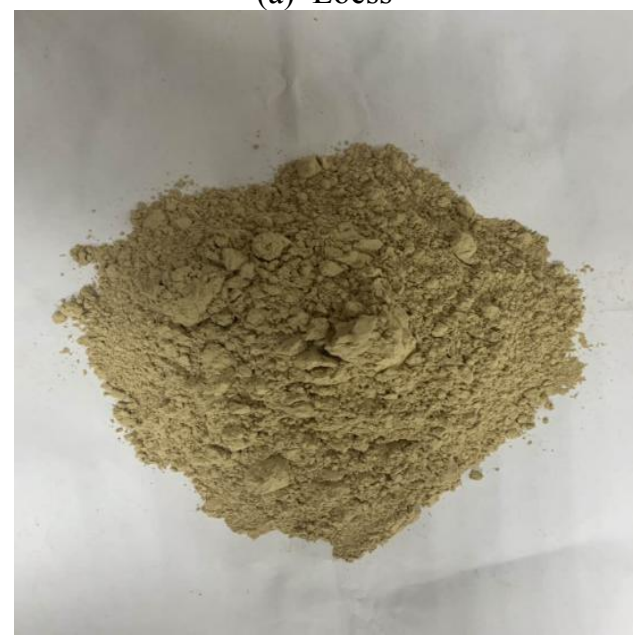

(b) Calcined ginger nuts

Fig. 1. Rammed material

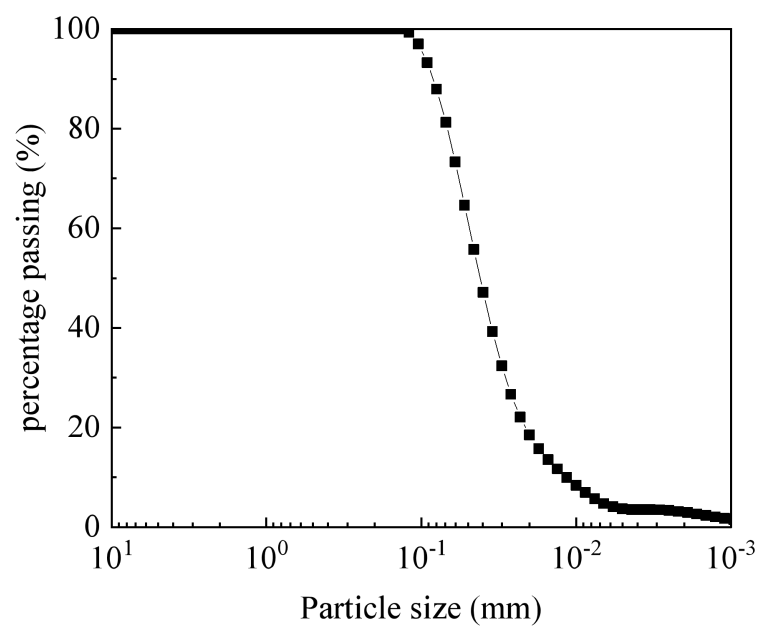

Fig. 2. Particle-size distributions curve of soil sample
Table 1. Basic physical properties of loess near Niutoucheng site in Lintan County

\begin{tabular}{|c|c|c|c|}
\hline $\begin{array}{c}\text { liquid } \\
\text { limit } \\
\left(\omega_{L} / \%\right)\end{array}$ & $\begin{array}{c}\text { plastic } \\
\text { limit } \\
\left(\omega_{P} / \%\right)\end{array}$ & $\begin{array}{c}\text { plasticity } \\
\text { index } \\
\left(I_{P}\right)\end{array}$ & $\begin{array}{c}\text { maximum } \\
\text { dry density } \\
\left(\mathrm{g} / \mathrm{cm}^{3}\right)\end{array}$ \\
\hline 28.52 & 12.28 & 16.24 & 1.61 \\
\hline $\begin{array}{c}\text { optimum } \\
\text { moisture } \\
\text { content } \\
(\%)\end{array}$ & $\begin{array}{c}\text { coefficient } \\
\text { of uniformity } \\
\left(\mathrm{C}_{u}\right)\end{array}$ & $\begin{array}{c}\text { coefficient } \\
\text { of } \\
\text { curvature } \\
\left(C_{c}\right)\end{array}$ & \\
\hline 14.10 & 4.25 & 1.45 & \\
\hline
\end{tabular}

Calcined ginger nuts curing mechanism [21] mainly includes:

(a) Hydration reaction

Calcined ginger nuts contains hydraulic cementing components $\beta-\mathrm{CaSiO}_{3}$ and $\mathrm{Ca}_{2} \mathrm{Al}_{2} \mathrm{Si}_{2} \mathrm{O}_{8}$, hydraulic components $\beta-\mathrm{CaSiO}_{3}$ and $\mathrm{Ca}_{2} \mathrm{Al}_{2} \mathrm{Si}_{2} \mathrm{O}_{8}$ and $\mathrm{H}_{2} \mathrm{O}$ rapid hydration reaction, $\quad \beta-\mathrm{CaO} \cdot \mathrm{SiO}_{2} \cdot \mathrm{nH}_{2} \mathrm{O}$ and $2 \mathrm{CaO} \cdot \mathrm{Al}_{2} \mathrm{O}_{3} \cdot \mathrm{SiO}_{2} \cdot \mathrm{nH}_{2} \mathrm{O}$ generation. At the same time, the nonhydraulic component $\mathrm{CaO}$ reacts with $\mathrm{H}_{2} \mathrm{O}$ first to form $\mathrm{Ca}(\mathrm{OH})_{2}$, so that it can be quickly cemented in the water environment to produce the initial strength. The reaction of modified ginger nuts in contact with water is as follows:

$$
\begin{gathered}
\beta-\mathrm{CaO} \cdot \mathrm{SiO}_{2}+\mathrm{nH}_{2} \mathrm{O} \rightarrow \beta-\mathrm{CaO} \cdot \mathrm{SiO}_{2} \cdot \mathrm{nH}_{2} \mathrm{O} \\
2 \mathrm{CaO} \cdot \mathrm{Al}_{2} \mathrm{O}_{3} \cdot \mathrm{SiO}_{2}+\mathrm{nH}_{2} \mathrm{O} \rightarrow 2 \mathrm{CaO} \cdot \mathrm{Al}_{2} \mathrm{O}_{3} \cdot \mathrm{SiO}_{2} \cdot \mathrm{nH}_{2} \mathrm{O} \\
\mathrm{CaO}+\mathrm{H}_{2} \mathrm{O} \rightarrow \mathrm{Ca}(\mathrm{OH})_{2}
\end{gathered}
$$

(b) Carbonation reaction

In the later stage, the nonhydraulicity component $\mathrm{CaO}$ reacts with $\mathrm{H}_{2} \mathrm{O}$ to generate $\mathrm{Ca}(\mathrm{OH})_{2}$, and then gradually absorbs $\mathrm{CO}_{2}$ from the soil and carbonizes to generate $\mathrm{CaCO}_{3}$. The above reaction process can be described as follows:

$$
\mathrm{Ca}(\mathrm{OH})_{2}+\mathrm{CO}_{2} \rightarrow \mathrm{CaCO}_{3}+\mathrm{H}_{2} \mathrm{O}
$$

\section{Methods}

Under the maximum dry density and optimum moisture content condition, quality fraction between loess and calcined ginger nuts is $0 \%, 4 \%, 8 \%$ for preparing rammed soil samples. Samples were made though static pressure method, the curing conditions are $25 \pm 2{ }^{\circ} \mathrm{C}$ indoor temperature and $30 \pm 2 \%$ indoor relative humidity.

\subsection{Disintegration test}

In disintegration test, the soil samples with length $*$ width $*$ height $(50 \mathrm{~mm} * 50 \mathrm{~mm} * 50 \mathrm{~mm})$ were used to conduct test, according to the Standard for Geotechnical Test Methods (GB/T50123-2019) [26]. The disintegration rate of the soil samples in different curing time was recorded. The age points of disintegration rate were 1 day, 7 days and 14 days. The 
calculation method of disintegration amount is shown in Equation (1).

$$
A_{t}=\frac{R_{t}-R_{o}}{R_{f}-R_{o}} \times 100
$$

where $A_{\mathrm{t}}$ is the disintegration rate of the sample at time point (\%), $R_{\mathrm{t}}$ is the reading at the surface of the float at time point, $R_{\mathrm{o}}$ is the instantaneous stable reading of the float at the beginning of the test, and $R_{f}$ is the reading of the float without sampling.

\subsection{Shrinkage test}

Soil samples with length $*$ width*height $(160 \mathrm{~mm} * 40 \mathrm{~mm} *$ $40 \mathrm{~mm}$ ) were used to test the shrinkage and quality loss of soil samples with different dosage at different time points. Because shrinkage and water loss of soil samples are significant in initial stage of maintenance, test node is 40 minute, 1 hour, 3 hours, 6 hours of time, and the test interval was 24 hours from the next day. The calculation formula of line shrinkage is shown in Equation (2).

$$
\delta_{i}=\frac{z_{i}-z_{o}}{z_{0}}
$$

where $\delta_{i}$ is the axial line shrinkage rate $(\%), Z_{i}$ is the length test value at test node $(\mathrm{mm})$, and $Z_{o}$ is initial length of sample ( $\mathrm{mm})$.

\subsection{Chroma difference test}

The chroma difference is one of the important parameters for evaluation of the protection and reinforcement of various cultural relics. This index can be used as a parameter to evaluate the influence of restoration on the appearance of the original site [27]. For earthen sites, the use of different materials or reinforcement techniques will lead to the chroma difference between the reinforcement area and the original soil area. Therefore, for the maintenance and protection of earthen sites, the chroma of the soil after reinforcement should not be different from that of the original earthen sites, and should conform to the principle of "repairing the old as the old". Therefore, it is necessary to carry out chroma difference test.

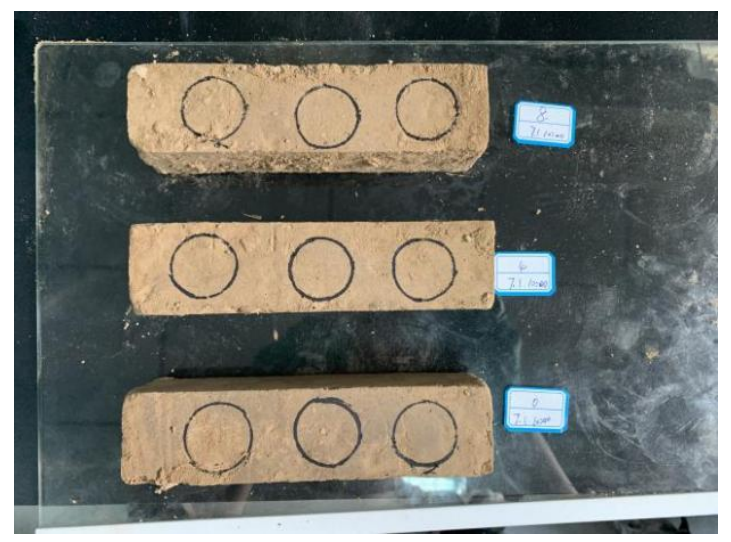

Fig. 3. Chroma test sample

Soil samples with length*width*height $(160 \mathrm{~mm} *$
$40 \mathrm{~mm} * 40 \mathrm{~mm}$ ) were used to conduct chroma test on soil samples. Three measuring points were selected in each soil sample, as shown in Figure 3. Set the test time is 40 minute, 1 hour, 3 hours, 6 hours of time, and the test interval was 24 hours from the next day. The chroma difference $\Delta \mathrm{E}_{\mathrm{ab}}$ can be calculated according to the formula (3).

$$
\Delta E_{a b}=\sqrt{(\Delta L)^{2}+(\Delta a)^{2}+(\Delta b)^{2}}
$$

where $\Delta \mathrm{L}$ represents the difference between light and shade. $\Delta \mathrm{a}$ represents the color difference between red and green, and $\Delta \mathrm{b}$ represents the difference between the yellow and blue.

\subsection{Unconfined compressive strength test}

Strength is the most important index in the evaluation system of the reinforcement effect of ramming. Therefore, it is necessary to carry out strength test. Soil samples with diameter $*$ height ( $\phi 61.8 \mathrm{~mm} * 125 \mathrm{~mm})$ were used to test the unconfined compressive strength of soil. The test age was the same as the disintegration test. The formula for calculating the compressive strength of soil samples is shown in Equation (4).

$$
\mathrm{q}_{\mathrm{u}}=\frac{\mathrm{p}_{\mathrm{t}}-\mathrm{p}_{\mathrm{o}}}{\mathrm{A}}
$$

where $q_{u}$ is the compressive strength of the soil sample $(\mathrm{MPa}), p_{t}$ is the maximum pressure of soil samples failure $(\mathrm{N}), p_{\mathrm{o}}$ is the pressure of the load just touching the soil samples $(\mathrm{N})$, and $\mathrm{A}$ is the cross-sectional area of the soil samples $\left(\mathrm{m}^{2}\right)$.

\subsection{Shear strength test}

Soil samples with diameter*height $(61.8 \mathrm{~mm} * 20 \mathrm{~mm})$ were used to conduct a rapid shear test. Shear rate is $0.8 \mathrm{~mm} / \mathrm{min}$ and axial pressure of $100 \mathrm{kPa}, 150 \mathrm{kPa}$ and $200 \mathrm{kPa}$. The shear performance under different dosage $(0 \%, 4 \%, 8 \%)$ was studied.

\section{Results and Analysis}

\subsection{Water stability of solidified loess}

The disintegration test results show that the final disintegration rate of the soil samples decreases with the increase of the dosage. Figure 4 shows the final state of samples disintegration under 14 days age. Soil samples of different dosage experience different processes in water, but they experience three stages early stage, middle stage and late stage. At the early stage of the test, appearance of bubbles on the surface without obvious disintegration, and the amount of disintegration is small at this stage. At the middle stage, the soil samples began to disintegrate from edges and corners, a small amount of disintegration occurs in the soil sample. In the late stage, with a large number of disintegration, the samples began to collapse. The samples with the dosage of $0 \%$ disintegrated completely, and the soil samples with the dosage of $4 \%$ collapsed into a pile of smaller particles, 
but the soil sample with the content of $8 \%$ collapsed into bulk fragments.

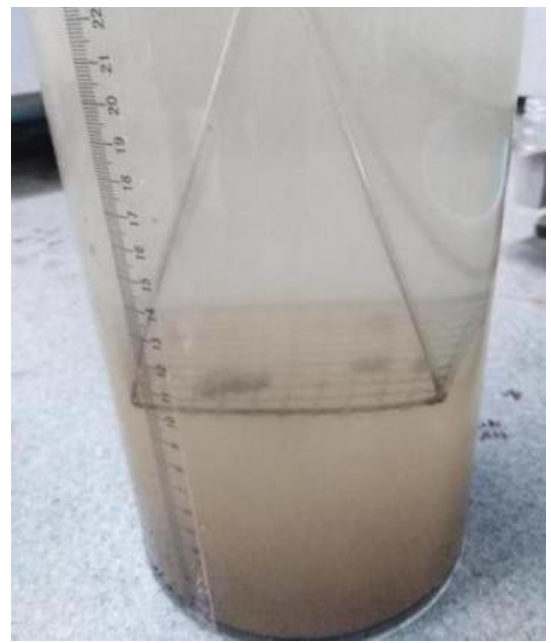

(a) Dosage of $0 \%$

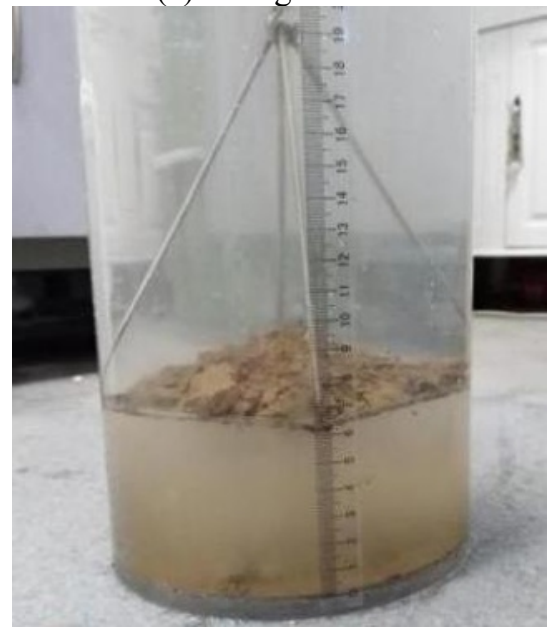

(b) Dosage of $4 \%$

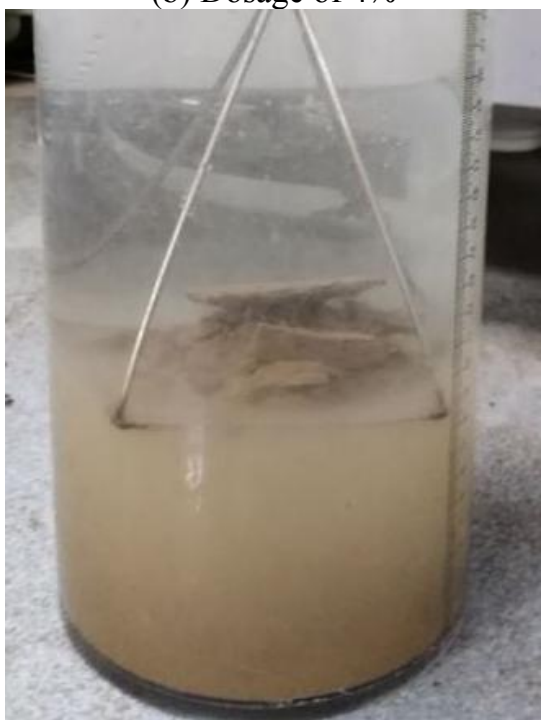

(c) Dosage of $8 \%$

Fig. 4. Disintegration state diagram of soil sample in later stage

The disintegration rate was calculated by Equation (1). The relationship among disintegration rate, different dosage and age of soil samples was analyzed. The analysis results are shown in Figure 5. The disintegration rate of soil samples with high dosage and long age is less, on the contrary, the disintegration rate of soil samples with low dosage and short age is large.

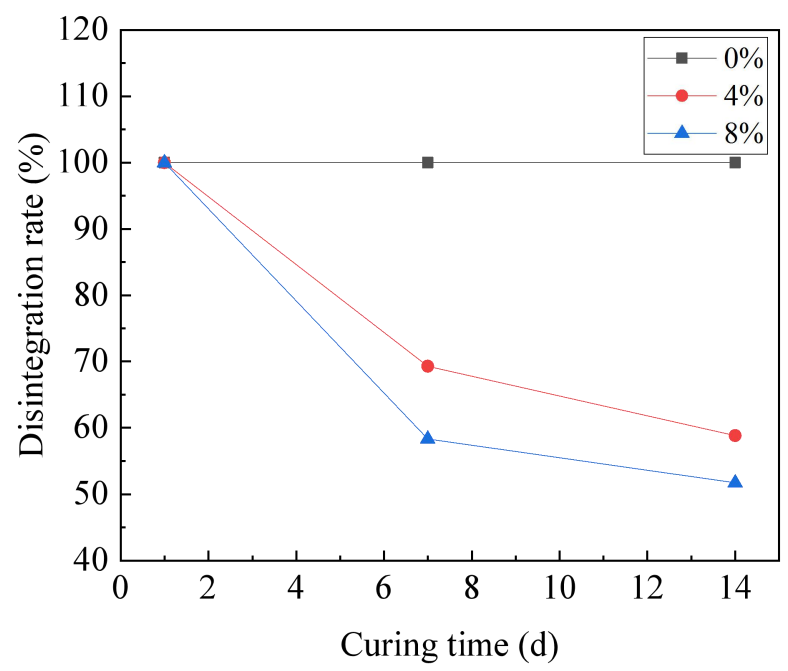

Fig. 5. Trend of disintegration rate

\subsection{Shrinkability}

Through the shrinkage test, the shrinkage rate along the length direction was calculated by Equation (2) and the quality changes of soil samples were obtained. Figure 6 and Figure 7 show linear shrinkage rate and quality loss of soil samples varies with curing time and dosage respectively. The results show that the shrinkage trend of soil samples with different dosage is similar, and shrinkage mainly occurs in the first two days after demoulding, but the shrinkage extent is slightly different. With the decrease of moisture content of soil, the volume of soil shrinks, and the linear shrinkage rate of soil samples will change. Comparing linear shrinkage rate of soil samples, quality loss of samples under different curing ages shows a similar change trend. When the moisture content of soil sample is high, the soil sample will appear rapid water loss and dry shrinkage. When the water content decreases, the shrinkage rate of soil samples decreases.

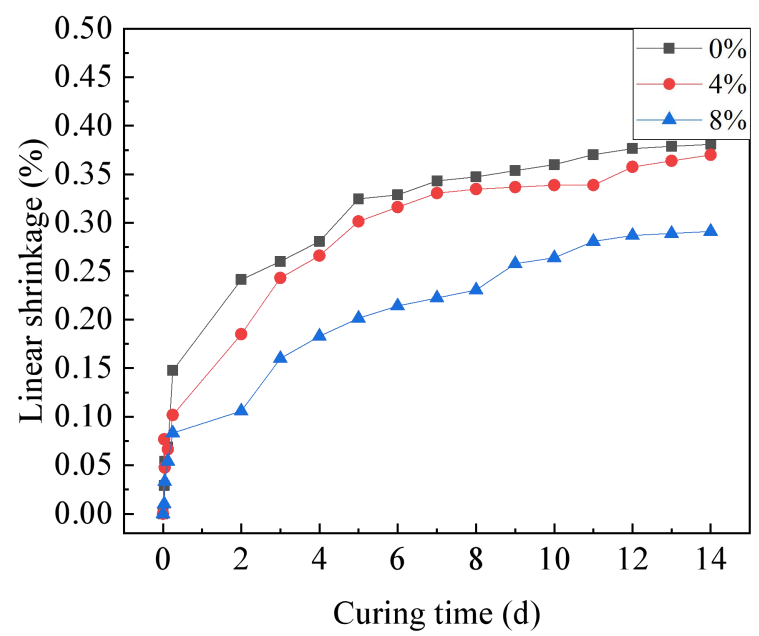

Fig. 6. Variation of linear shrinkage of soil samples 


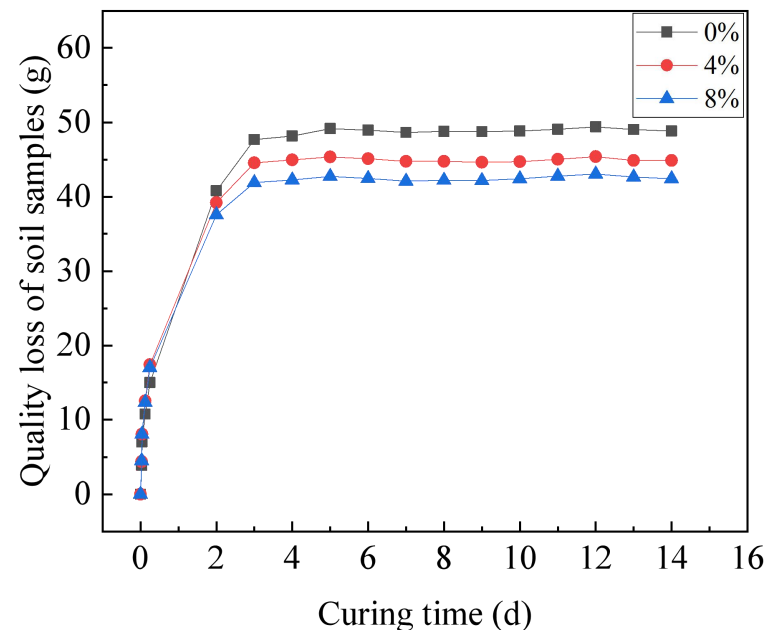

Fig. 7. Variation of soil samples quality

\subsection{Chroma difference}

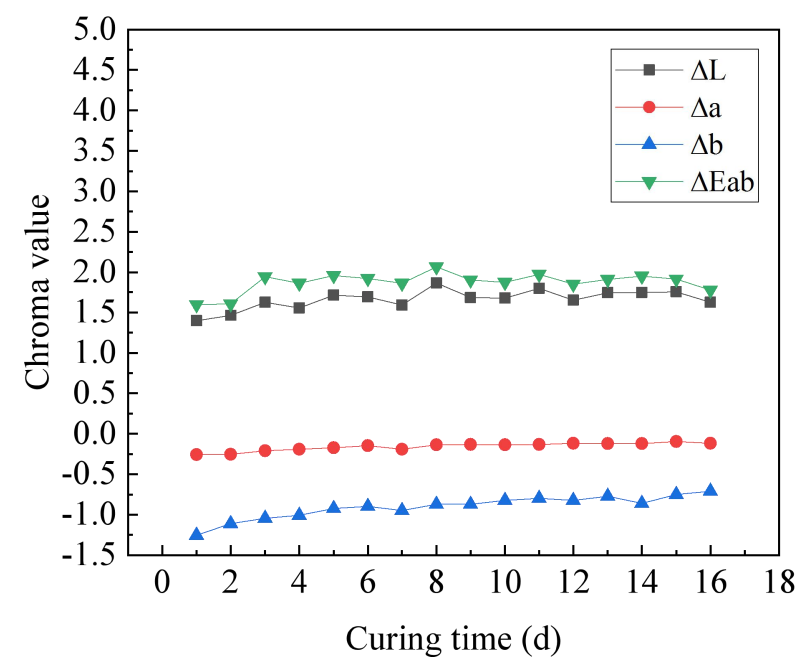

Fig. 8. Variation of chroma value with $4 \%$ dosage

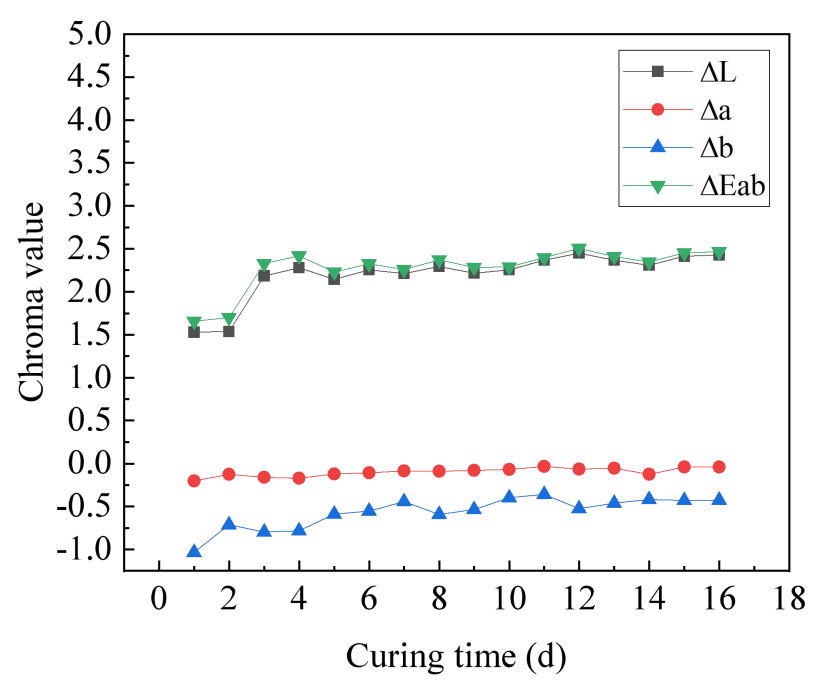

Fig. 9. Variation of chroma value with $8 \%$ dosage

After demoulding, the chroma of the soil samples was measured, and each dosage was measured at three points each time. The difference values of $\Delta \mathrm{L}, \Delta \mathrm{a}$ and $\Delta \mathrm{b}$ of soil samples were calculated according to the test results, and the chroma difference values $\Delta \mathrm{E}_{\mathrm{ab}}$ were calculated according to Formula (3). For $4 \%$ and $8 \%$ dosage soil samples, the calculation results of surface chroma after 16 days are shown in Figure 8 and Figure 9 respectively.

The results show that calcined ginger nuts dosage makes the surface color change slightly. Compared with the soil samples without calcined ginger nuts, indexes $\Delta \mathrm{a}$ and $\Delta \mathrm{b}$ of solidified soil are less change, and various trend are similar. However, $\Delta \mathrm{L}$ change obviously, and the value of $\Delta \mathrm{E}_{\mathrm{ab}}$ is similar with $\Delta \mathrm{L}$. Therefore, the degree of light and shade of the surface color of earthen sites is the main influencing factor of chroma difference. The chroma difference values of samples with $4 \%$ and $8 \%$ dosage are basically 1.9 and 2.4 , and they are all less than 3 , which can satisfy the requirement of earthen sites protection [28].

\subsection{Unconfined compressive strength}

Unconfined compressive strength tests were carried out on soil samples, the test results are shown in Figure 10.

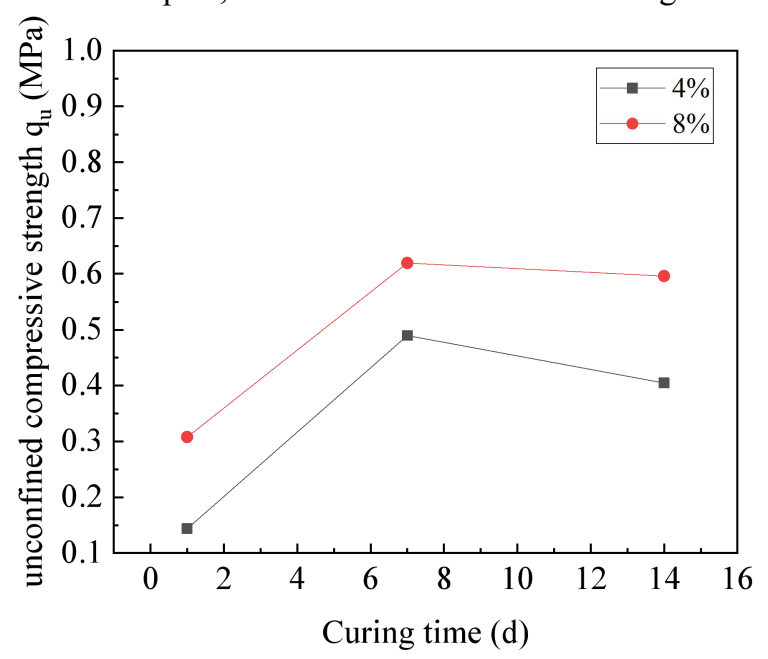

Fig. 10. Change of unconfined compressive strength

Figure10 shows the variation of the unconfined compressive strength of soil samples with different age and dosage. At the same age, with the increase of calcined ginger nuts dosage unconfined compressive strength increased. As increase of age, the unconfined compressive strength increases and then decreases. Because hydration reaction between the calcined ginger nuts and water dominants compressive strength in initial curing time, so the early strength is improved significantly. In the late stage, carbonation reaction is gradually obvious, nonhydraulicity component in calcined ginger nuts reacts with carbon dioxide in the air. At the same time, the reaction results heat releasing and air flow in curing stone body [29]. Therefore, the porosity of soil sample increases and the compressive strength decreases slightly in the later stage.

\subsection{Shear strength}

The shear strength test was carried out on the soil samples. After 14 days of curing, the relationship curve between shear stress and shear displacement under 
different dosage was measured, as shown in Figure 11.

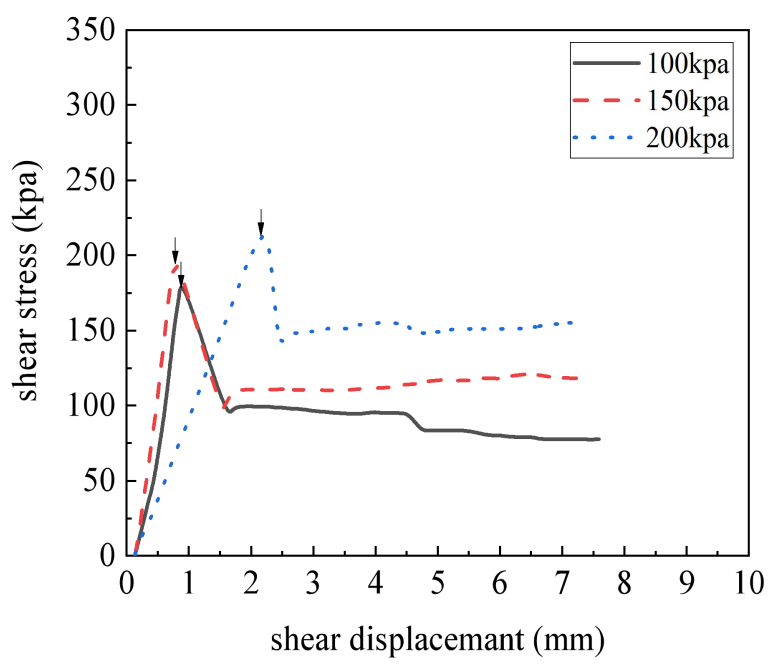

(a) Dosage of $0 \%$

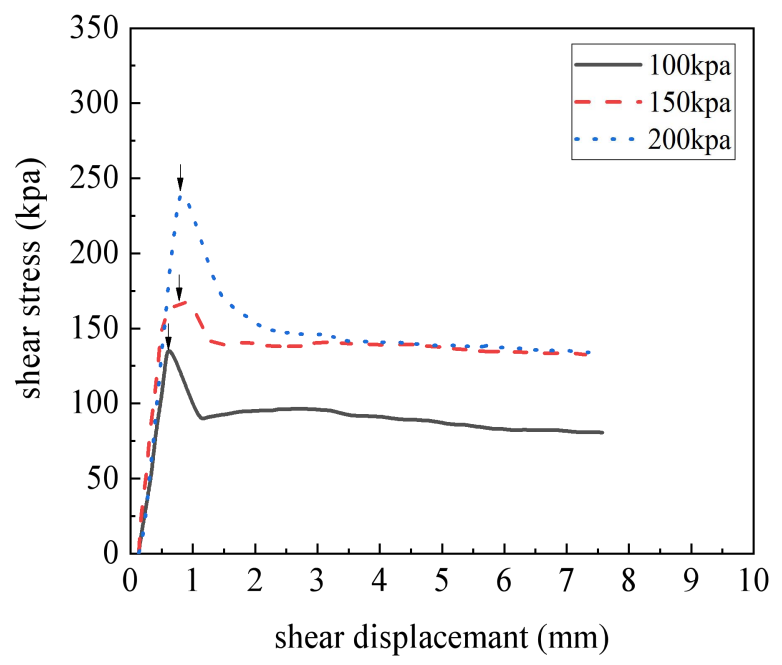

(b) Dosage of $4 \%$

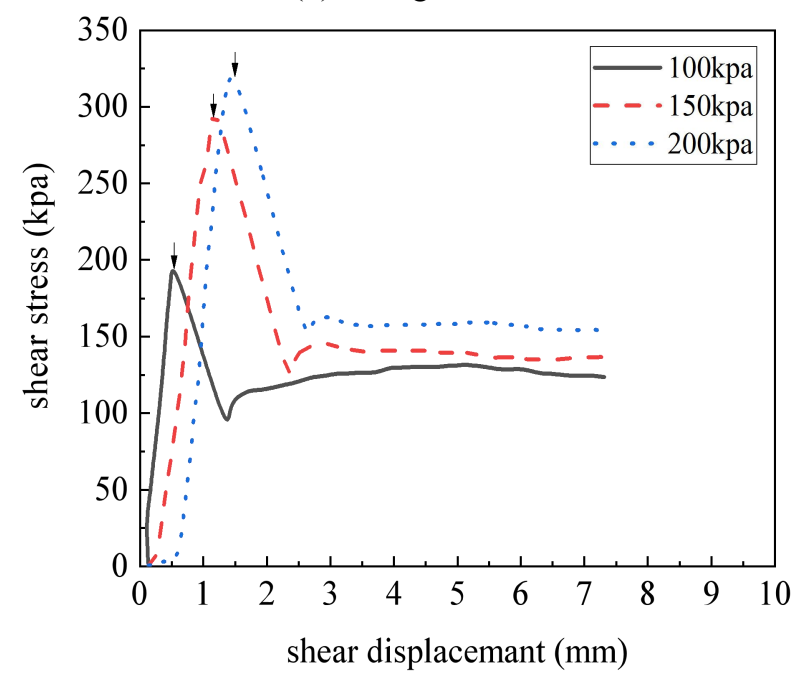

(c) Dosage of $8 \%$

Fig. 11. Shear stress-displacement curve of soil sample after 14 days curing

Figure 11 shows the shear stress-displacement curve of samples. As shown in the figure, compared with low dosage, the strength of samples with high dosage is higher. The shear stress-displacement curves of all samples experienced rising, falling and stable stages under different dosage. In the rising stage, the slope of shear stress-displacement curve is similar during shear stress increases to the peak value. In the falling stage, tiny crack will appear and continue to expand and gradually form a perforating flat crack, and the soil samples are cut into two parts. Therefore, the shear strength begins to decrease. In the stable stage, the shear stress drops very slowly and is relatively stable, and the soil samples have been completely destroyed at this stage.

\section{Conclusions}

Ramming is a very effective method to reinforce the sapping area. The use of rammed earth materials will impact the effect of ramming. Therefore, the weatherability, chroma and mechanics of the solidified soil using the calcined ginger nuts were studied in the laboratory test.

The introduction of calcined ginger nuts can effectively improve the resistance of soil to disintegration and shrinkage. The rate of soil disintegration decreases with the increase of dosage and age. The shrinkage trend of soil samples with different dosage is similar. The shrinkage rate of samples changes rapidly in the early stage, but the shrinkage degree of soil samples with different dosage is different, and compared with low dosage, the shrinkage of soil samples of high dosage is smaller. Calcined ginger nuts makes the surface color of soil samples change slightly when the dosage is lower, and the main change is the degree of light and shade.

Compared with low dosage, the strength of high dosage samples is higher. Moreover, with the increase of age, the unconfined compressive strength showed an increasing trend in the early stage and decreased in the later stage. The reason is that hydration reaction between the calcined ginger nuts and water dominants compressive strength in initial curing time. In the late stage, carbonation reaction is gradually obvious. At the same time, the reaction results heat releasing and air flow in curing stone body. Therefore, the porosity of soil sample increases and the compressive strength decreases slightly in the later stage. The shear strength of samples with high dosage is higher. The changing trend of shear stress-displacement curve of soil samples with different dosage is similar, and the curve has experienced rising, falling and stable stages during the test.

\section{Acknowledgments}

This work has been supported by the National Natural Science Foundation of China (41901079, 41971093), Independent Research Project of State Key Laboratory of Frozen Soil Engineering (SKLFSE-ZQ-50) and the Foundation for Excellent Youth Scholars of NIEER, CAS (Y9510608).

\section{References}

[1] E. Fodde, Traditional earthen building techniques in 
central Asia, Int J Archit Herit, 3,145-168 (2009)

[2] A. A. Charnov, 100 years of site maintenance and repair: conservation of earthen archaeological sites in the American Southwest, Journal of Architectural Conservation, 17, 59-75 (2011)

[3] E. Fodde, Structural faults in earthen archaeological sites in central Asia: analysis and repair methods, in Proceedings of the 6th International Conference on Structural Analysis of Historic Construction, 1415-1422 (2008)

[4] P. A. Jaquin, C. E. Augarde, and C. M. Gerrard, Chronological description of the spatial development of rammed earth techniques, Int $J$ Archit Heri: Conservation, Analysis, and Restoration, 2, 377-400 (2008)

[5] F. Pacheco-Torgal and S. Jalali, Earth construction: lessons from the past for future eco-efficient construction, Constr Build Mater, 29, 512-519 (2012)

[6] L. Li, M. Shao, S. Wang, Preservation of earthen heritage sites on the Silk Road, northwest China from the impact of the environment, Environ Earth Sci, 64, 1625-1639 (2011)

[7] Y. Fujii, E. Fodde, K. Watanabe, and K. Murakami, Digital photogrammetry for the documentation of structural damage in earthen archaeological sites: the case of Ajina Tepa, Tajikistan, Eng Geol, 105, 124-133 (2009)

[8] E. Fodde, K. Watanabe, and Y. Fujii, Preservation of earthen sites in remote areas: the Buddhist monastery of Ajina Tepa, Tajikistan, Conservation and Management of Archaeological Sites, 9, 194-218 (2007)

[9] P. Jaquin, Study of historic rammed earth structures in Spain and India, Struct Eng, 86, 26-32 (2008)

[10] H. Y. Zhao, Z. X. Li, W. F. Han, X. D. Wang, and W. W. Chen, Main diseases and their causes of earthen ruins in arid region of Northwestern China, Chinese Journal of Rock Mechanics and Engineering, 22, 2875-2880 (2003), In Chinese

[11] Q.-B. Bui, T.-T. Bui, R. El-Nabouch, D.-K. Thai, Humberto Varum, Vertical Rods as a Seismic Reinforcement Technique for Rammed Earth Walls: An Assessment, Adv Civ Eng, 2019 (2019)

[12] P. Jaquin, Study of historic rammed earth structures in Spain and India, Struct Eng, 86, 26-32 (2008)

[13] Z. X. Li, Research on protection and reinforcement of earthen sites of ancient silk road in China, Academic Report on the 60th Anniversary of the Founding of Gansu Pprovince Chemical Society and the 23rd Annual Meeting Proceedings, (2003), In Chinese

[14] Z. Dong, et al., Experimental Studies on Earthen Architecture Sites Consolidated with BS Materials in Arid Regions. J Eng, 1-13 (2016),

[15] J. Q. Zeng, P. F. Chen, J. K. Zhang, Evaluation of reinforcement effect of ramming roof for simulated archeological soil sites in humid environment,
Sciences of Conservation and Archaeology, 28, 78-84(2016), In Chinese

[16] K. Liu, M. Wang, and Y. Wang, Seismic retrofitting of rural rammed earth buildings using externally bonded fibers, Constr Build Mater, 100, 91-101 (2015)

[17] Y. Melloh, Pull-down test of the rammed earth walls at Paga Lhakhang in the kingdom of bhutan, Sustainable Construction and Design, 303-311 (2014)

[18] Y. Wang, M. Wang, et al., Shaking table tests on seismic retrofitting of rammed-earth structures, $B$ Earthq Eng, 15, 1037-1055 (2016)

[19] L Miccoli, U Miller, P Fontana, Mechanical behaviour of earthen materials: A comparison between earth block masonry, rammed earth and cob, Constr Build Mater, 61, 327-339 (2014)

[20] P. C. Zhang, S. D. Lang, Study on the Geochemical Characteristics of Dadiwan Site in Qinan, Gansu Province, Cultural Relics, 21-30, (1983), In Chinese

[21] L. Li, L. Y. Zhao, Research on Ancient Lime Materials in China, Cultural Relics Publishing House, 297-354 (2015), In Chinese

[22] Z. X. Li, X. D. Wang, M. L. Sun, W. W. Chen, Q. L. Guo, H.Y. Zhang, Conservation of Jiaohe ancient earthen site in China, $J$ Rock Mech Geotech, 3, (2011)

[23] Z. X. Li, L. Y. Zhao, L. Li, et al., Research on the modification of two traditional building materials in ancient China, Herit Sci, 1, (2013)

[24] J. K. Zhang, W. W. Chen, Z. X. Li, X. D.Wang,Q. L. Guo,N. Wang, Study on workability and durability of calcined ginger nuts-based grouts used in anchoring conservation of earthen sites, $J$ Cult Herit, 16, (2015)

[25] L. Y. Zhao, L. Li, Z. X. Li , J. H. Wang, Study on two traditional silicate materials in ancient Chinese architecture, Journal of Inorganic Materials, 26, 1327-1334 (2011), In Chinese

[26] Nanjing Institute of Water Resources and Hydropower Research. GB/ T 50123-2019 Standard for Geotechnical Test Method. Beijing: China Water Resources and Hydropower Press, (2019), In Chinese

[27] Y. Rong, Application of Colorimetry in Archaeology of Cultural Relics, Journal of Xianyang Normal University, 4, 22-25(2014), In Chinese

[28] J. F. Zhang, Evaluation of color difference in chemical reinforcement protection of earthen ruins, China cultural Heitage Scenific Reserch, 51-57 (2016), In Chinese

[29] W. C. Chen, S. J. Wang, L. Li, X. B.Zhang, Y. B. Wang, Experimental study on mechanical properties of modified ginger nuts material, Rock Soil Mech, 39, 1796-1804(2018), In Chinese 